\title{
GNNS CONTROL NETWORK SUPPORTING LARGE HISTORICAL BUILDING ARCHITECTURAL SURVEY
}

\author{
V. Bonora ${ }^{1}$, R. Maseroli ${ }^{1}$, F. Mugnai ${ }^{1 *}$, G. Tucci ${ }^{1}$ \\ ${ }^{1}$ Department of Civil and Environmental Engineering, University of Florence, via di S.Marta, 3 - 50139 Firenze, Italy - \\ (valentina.bonora, francesco.mugnai, grazia.tucci)@unifi.it; \\ maseroli@tin.it
}

KEYWORDS: GNSS, Geodetic reference frame, Photogrammetry, Drone, LIDAR

\begin{abstract}
:
The paper points the attention to some hidden parts of metric surveys, that usually are not enough documented in scientific papers but in technical reposts. Reporting encountered challenges and discussing identified technical solutions and methodologies to overcome bottlenecks and operative issues, highlights the novelty of the presented experience from a technical viewpoint. The overall approach has been reported taking care of describing technical details and present case study's implementation of the applied techniques. Integrating GNSS control Networks and topographic tools to design, implement and perform a rigorous topographic survey methodology in describing built heritage, which is one of the modern geomatics' advancements, has been depicted. An ad hoc datum has been designed to guarantee a clear compliance both to cartographic standards and architectural representations in 1:50 to 1:100 graphical output scale.
\end{abstract}

\section{PRIMARY CONTROL NETWORK IN ARCHITECURAL FIELD}

The architectural survey has made extensive use of topographic tools (first) and geomatics (later) to add objectivity and metric rigour to the description of the built heritage in recent times (da Silva et al., 2017; Y. Y. W. Yang, 2007; Yanrong et al., 2010). The geometric survey, which has always been a crucial tool to understand architecture, has acquired in this way the rigorous form of cartography. It has also integrated the wealth of photogrammetry information and quickly grasped the potential of 3D scanning systems (Bonora et al., 2021; Mugnai et al., 2021; Wang et al., 2017). Even if formal interpretation retains a primary role in studying a monument, the spread of highresolution digitization systems often involves the split between the analysis and measurement phases, anticipating the latter to the first one.

The lack of specific norms and standards and following rare examples of technical specifications, which often seem to have lost the rigour of the interesting episodes of the early 2000s (Balletti et al., 2000), makes defining the "quality" of an architectural survey challenging.

A multiplicity of aspects participates in its definition; most of them, such as effectiveness, completeness, and manageability, cannot be easily quantified and expressed objectively and have a wide and subjective variation field. Accuracy is, on the contrary, one of the objective aspects qualifying a survey, but this is true only if it has been designed and built with rigorous procedures and methods. A geodetic reference frame is essential to allow both the correct georeferencing of the survey and ensure uniform accuracy. Both aspects are particularly relevant in large, monumental buildings, such as the case study presented in the paper: the Pitti Palace (Figure 1) in Florence (Italy).
Furthermore, the geometric survey of buildings of considerable historical and artistic value, aimed at future recovery or conservative restoration interventions, requires high precision and graphical outputs at the scale of 1:50 $\div 1: 100$.

The paper further describes the choices adopted for the design, construction, calculation, and adjustment control network and its ad-hoc defined cartographic projection. In this way, the horizontal coordinates and elevations of the vertices have been appropriately determined, and it has been possible to reference the detailed survey made by integrating 3D scanning systems and digital photogrammetry.

\section{FRAMEWORK REFEERNCE SYSTEM}

To appropriately include detailed surveys in existing official documents such as regional technical cartography or municipal regulatory plan, the coordinate system must be consistent with the standard Italian Geodetic Reference System (Maseroli, 2013).

\section{Planimetric reference system}

Since 2011, the official Italian Geodetic System consists of the ETRF2000 implementation of the ETRS89 Global System; it allows the direct use of GNSS techniques (Crainic, n.d.; Devoti et al., 2014; Halim et al., 2019; Tarig, 2012), which, if properly applied, allow for reach high precision observations without the need for the points to be intervisible (Figure 2).

\section{Altimetric reference system}

These techniques (Abd-elqader et al., 2020; Arun et al., 2018; Veronez et al., 2011), however, have the drawback of providing ellipsoidal heights devoid of physical significance. The needs of operating with geodetic heights foster transforming the heights obtained from the satellite survey.

\footnotetext{
* Corresponding author
} 
This result can be obtained by using, within the Italian territory, the ITALGEO2005 national geoid model, created by the Polytechnic of Milan and published by the Military Geographical Institute, which is characterized by a mean square error of $3.5 \mathrm{~cm}$

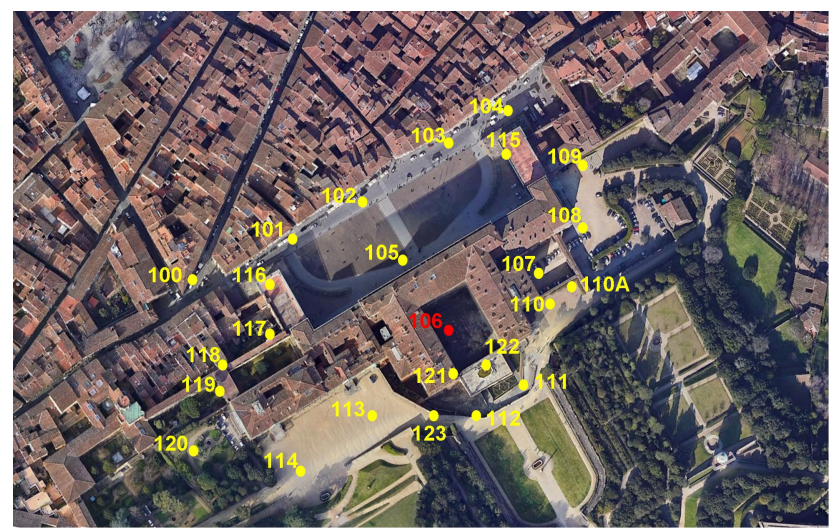

Figure 1 - Map of the reference network's points.

To improve the altimetric accuracy, it is advisable to locally adapt the geoid model through a Helmert roto-translation or, if local conditions allow it, by applying a more straightforward method on points with hi-reliability geoid altitude, such as the benchmarks belonging to the National High Precision Levelling Network. Since one of them is available on Palazzo Pitti, it has been possible to adapt the geoid locally (Okiemute et al., 2018; Oluyori et al., 2019; C. A. O. Yang \& Insitute, 2013), obtaining uncertainties of less than one centimetre.

\subsection{Plane coordinates}

Returning collected data in plane coordinates is convenient for multiple reasons and can be easily obtained using the plane projection associated with the Global Geodetic System, in our case, the TM32 -Transverse Mercator, zone 32. However, the coordinates thus projected present the drawback of being affected by both cartographic and height deformations. Characteristics of the projection the first, due to the height of the working area the latter. Designing an ad hoc one, instead of adopting a standard plane projection, is therefore advisable. In this way, although the projection remains conformal, the coordinates are very close to isometry. Therefore, the difference between real and projected distances is negligible, even considering the high accuracy required for a very large-scale survey.

\section{CONTROL NETWORK}

\subsection{The Palazzo Pitti setting}

The Palazzo Pitti is a large, palace in Florence, Italy. It is situated on the south side of the River Arno, in the nearby of Ponte Vecchio. The palace has the considerable size of $320 \mathrm{x}$ $170 \mathrm{~m}$, more than 100 rooms and vaste external areas. The surroundings are heavily built up, apart for the main NO square and SE gardens, the other internal courtyards have a limited sky view which pose serious issues for GNSS observations.

\subsection{Designed control network}

Following a careful survey's requirements analysis, the control network's characteristics have been identified as follows:
- Three-dimensional with geodetic heights;

- Centimetric relative accuracy, which is compliant with architectural cartographic restitution's detail.

- framed in the current national official reference, the ETRF2000 Global System; to be immediately compatible with the coordinates obtained from the GPS.

\subsection{Calculating planimetric coordinates, tools and methods}

A GPS station was performed on the 20 points of the reference network. Excluding point n 106, which is located in the center of the Ammannati courtyard, the observations have been acquired with good satellite visibility and lasted for a minimum time span of 2 hours each one. The instrumentation consisted on a TRIMBLE R10 receiver equipped with a geodesic antenna.

The observations were obtained with various closed transverse networks, 7 of which included the permanent station IGM2, belonging to the Military Geographical Institute, and included in the official Italian network RND. In this way including the survey in the ETRF2000 global reference has been possible. Figure 2 shows the graph of the 30 determined baselines. Point 106's position, which couldn't be observed using GNSS receiver for coverage limitations, has been determined with classical methodologies as reported in section 3.7.

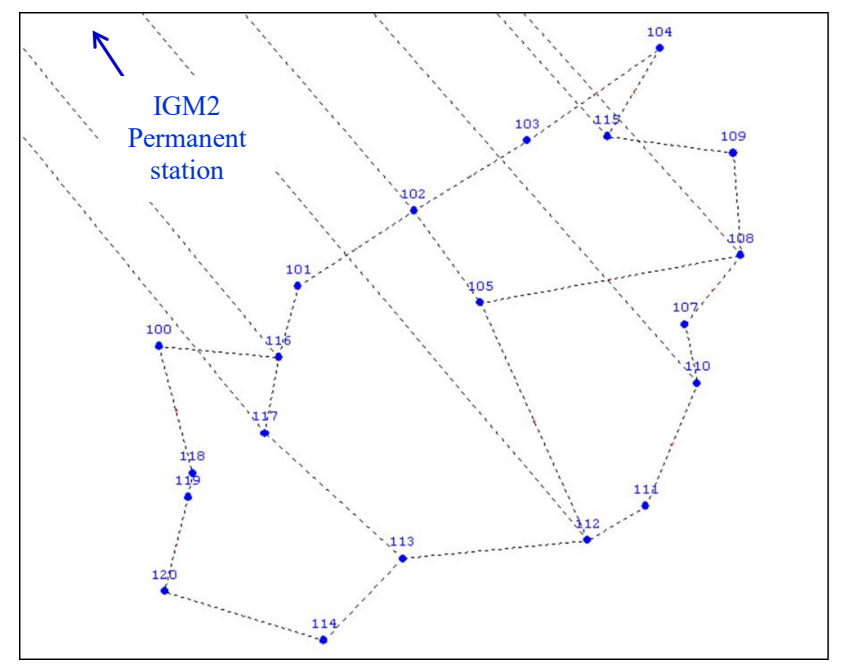

Figure 2 - Determined baselines to the IGM2 permanent station.

\subsection{Least squares compensation}

Having thus verified the validity of the measurements, we proceeded, using the GEOLAB software, to a least squares adjustment of all the measured baselines, the salient elements of which are summarized below and demonstrate the achieved considerable degree of precision:

a) Redundancy $=1.5$;

b) MSE of the weight unit (confidence $95 \%$ ) $=3 \mathrm{~mm}$,

The average of the semi-major axes of the absolute error ellipses, again at the $95 \%$ confidence level, is $7 \mathrm{~mm}$, while the average of the vertical component's absolute errors is equal to $15 \mathrm{~mm}$.

More interesting, for the purposes of this study, are the relative errors amongst the points of the survey, that have a direct influence on the geometry of the object. These quantities, always expressed at a 95\% confidence level, are equal to $6 \mathrm{~mm}$ for the planimetry and $12 \mathrm{~mm}$ for the vertical component. 


\subsection{Measurements' prior check}

The sum of the baselines that bind the unknown points to each other was performed to check the measurements' quality; closed circuits have been followed and the bases have been grouped in the 4 polygons numbered from 1 to 4 (Figure 3 ).

Figure 3 - Polygons for closed transverse networks.

The results, summarized in Table 1 , ensure the required observations' quality. Using the baselines that tie the known point IGM2 to the unknown points, the same verification has been also carried out, grouping them in 4 polygons numbered from 5 to 8 .

\subsection{Tools and methods for calculating elevation coordinates}

The results obtained for the framing network, based on GPS surveys, are totally satisfactory in terms of accuracy for supporting the detailed surveys. However, as the ellipsoidal heights are only provided, which contain geometric validity but are devoid of physical meaning and are not therefore totally satisfactory for all applications. Starting from the ellipsoidal heights from the GPS surveys, the heights referred to the geoid were obtained using the ITALGEO2005 national geoid model, calculated by the Politecnico di Milano in collaboration with the IGM, and based on gravimetric measurements (Barzaghi R., Borghi A., Carrion D., 2007).

\subsection{Local adaptation of the geoid model}

The accuracy of the geoid model can be improved through a local adaptation of the surface (Chenguang, 1996; Guo et al., 2017; Okiemute et al., 2018), an operation for which it is necessary to have geometric leveling dimensions in the area of interest.

Table 1 -Checks on closed levelling lines.

On the Palazzo Pitti building there is a leveling benchmark belonging to the National High Precision Leveling Network (Pirsan, 2018; Xinsheng, 2010), and precisely n. 3IV of line 154, consisting of an anonymous nail fixed into the threshold of the main entrance of the building, a few meters from point 105 of the framing network (Bo, 2008; Cefalo et al., 2011).

Through geometric leveling measurements, the height of 105 point was calculated, which was equal to $57,108 \mathrm{~m}$. On 105 point the difference between the height obtained by leveling and that deriving from the geoid model was $+13 \mathrm{~mm}$. In consideration of the limited extension of the area affected by the survey, the local adaptation of the geoid model was obtained through a simple upward translation of $0.013 \mathrm{~m}$. Height of point 106 , planimetrically determined by intersection, was obtained by precision geometric leveling from point 105; with the same procedure, point 107 was also processed as characterized by an ellipsoidal elevation that was not fully satisfactory.

For points 106 and 107 the ellipsoidal elevation was therefore obtained starting from the geoid elevation by applying the locally adapted geoid model.

In this way planoaltimetric definition (with geoidal heights) of a high-precision control network has been obtained and it is consistent with the national official Geodetic Reference System

\begin{tabular}{|c|c|c|c|c|c|c|c|c|}
\hline Num. & $\begin{array}{c}\text { Latitudine } \\
\text { [sessagesimal] }\end{array}$ & $\begin{array}{c}\text { Longitudine } \\
\text { [sessagesimal] }\end{array}$ & $\begin{array}{c}\text { Nord TM32 } \\
{[\mathrm{m}]}\end{array}$ & $\begin{array}{c}\text { Est TM32 } \\
{[\mathrm{m}]}\end{array}$ & $\begin{array}{c}\text { Heigh } \\
\text { elliss. } \\
{[\mathrm{m}]}\end{array}$ & $\begin{array}{c}N \\
{[\mathrm{~m}]}\end{array}$ & $\begin{array}{c}\text { H } \\
\text { geoid. } \\
{[\mathrm{m}]}\end{array}$ & $\begin{array}{c}\text { H geoid. } \\
\text { adapted } \\
{[\mathrm{m}]}\end{array}$ \\
\hline 100 & $43^{\circ} .45^{\prime} 54,5449^{\prime \prime}$ & $11^{\circ} .14^{\prime} 53,3535^{\prime \prime}$ & 4848245.548 & 680955.246 & 94.134 & 45.287 & 48.847 & 48.860 \\
\hline 101 & $43^{\circ} .45^{\prime} 55,4045^{\prime \prime}$ & $11^{\circ} .14^{\prime} 56,0962^{\prime \prime}$ & 4848273.734 & 681015.850 & 95.792 & 45.285 & 50.507 & 50.521 \\
\hline 102 & $43^{\circ} .45^{\prime} 56,4916^{\prime \prime}$ & $11^{\circ} .14^{\prime} 58,3848^{\prime \prime}$ & 4848308.661 & 681066.109 & 96.719 & 45.282 & 51.437 & 51.450 \\
\hline 103 & $43^{\circ} .45^{\prime} 57,5002^{\prime \prime}$ & $11^{\circ} .15^{\prime} 00,6177^{\prime \prime}$ & 4848341.136 & 681115.188 & 96.840 & 45.280 & 51.560 & 51.574 \\
\hline 104 & $43^{\circ} .45^{\prime} 58,8226^{\prime \prime}$ & $11^{\circ} .15^{\prime} 03,2435^{\prime \prime}$ & 4848383.530 & 681172.789 & 95.675 & 45.277 & 50.398 & 50.412 \\
\hline 105 & $43^{\circ} .45^{\prime} 55,1718^{\prime \prime}$ & $11^{\circ} .14^{\prime} 59,6909^{\prime \prime}$ & 4848268.738 & 681096.419 & 102.379 & 45.284 & 57.095 & 57.108 \\
\hline 106 & $43^{\circ} .45^{\prime} 53.6779^{\prime \prime}$ & $11^{\circ} .15^{\prime} 00,8621^{\prime \prime}$ & 4848223.359 & 681123.859 & 103.202 & 45.287 & & 57.928 \\
\hline 107 & $43^{\circ} .45^{\prime} 54,8570^{\prime \prime}$ & $11^{\circ} .15^{\prime} 03,7316^{\prime \prime}$ & 4848261.482 & 681187.028 & 103.441 & 45.284 & & 58.170 \\
\hline$\ldots$ & $\ldots \ldots$ & $\ldots \ldots$ & $\ldots \ldots$ & $\ldots \ldots$ & $\ldots \ldots$ & $\ldots \ldots$ & $\ldots \ldots$ & $\ldots \ldots$ \\
\hline
\end{tabular}

Table 2 - Final coordinates of the framing grid in the ETRF2000 System ( $\quad$ in blue classical measurements, the geoid elevations in red were measured with leveling, the ellipsoidal heights in red were obtained from the geoidic ones through application of the locally adapted geoid model.

This model is provided by means of the separation values

(N) referred to a regular step closed travers network, and is characterized by a standardized mean square error equal to 3.5 $\mathrm{cm}$. The geoidal heights of all points (values shown in table 2) were calculated by subtracting from the ellipsoidal ones the separation values that belong to each point of the (ETRF2000). It is also characterized by mean square errors of less than one centimeter, therefore certainly sufficient to constitute an adequate support for the detailed surveys that will be carried out with the characteristic accuracies of the scale 1:50 $\div 1: 100$. 


\subsection{Isometric plane coordinates}

For multiple reasons it is convenient to return the observed data, and proceed to the subsequent processing, using the plane coordinates, which could be easily obtained using the plane projection associated with the Global Geodetic System adopted, in our case the TM32.

However, these coordinates, have the drawback of being affected by deformations both cartographic, characteristics of the projection, and height, due to the elevation of the working area.

To have plane coordinates, practically free of deformations (Barzaghi et al., 2014), it is advisable not to adopt a standard projection, such as the TM32, but to design an ad hoc one, which allows to obtain coordinates as close as possible to the isometry. In this way, calculating very similar distances to the real one that can be directly measured, if not perfectly equal, will be possible, and represents a crucial performance in an architectural survey.

\subsection{Height deformation}

In addition to the deformation induced by the cartographic projection, it is therefore necessary to consider that the real distances between points above the ellipsoid (i.e. with heights $>$ 0 ) are always elongated with respect to the reference surface, and that the expansion is a function of the height (height deformation). The modulus ( $\mathrm{k}$ ) of this deformation, which is always positive, can be obtained from the simple relation:

$$
\mathbf{k}=\mathbf{1}+\mathbf{h} / \mathbf{R}
$$

where $\mathrm{h}$ is the height at which the distance is measured, and $\mathbf{R}$ is the radius of the mean local sphere.

The height deformation introduces an expansion of about $1 \mathrm{ppm}$ every $6 \mathrm{~m}$ of height. The overall deformation is obtained by considering both two mentioned effects which are added algebraically:

\section{height deformation + cartographic deformation.}

\subsection{Designing the ad-hoc cartographic representation}

Given that the height deformation is unavoidable while the cartographic one can be, at least in part, governed by choosing an appropriate projection and suitably varying the parameters that characterize it, it is effective to look for a plane projection that presents linear deformations, point by point, the most possible close to the height deformations, so that the final residual deformation is as small as possible.

Using a conformal projection is also advisable to keep the angles unchanged.

In the present case, given the limited extent of the surveyed area, the variability of the altitudes is very limited: from a minimum of $94 \mathrm{~m}$ to a maximum of 120 , and consequently also the height deformation has a very limited range: from 15 to $19 \mathrm{ppm}$.

To equalize these quantities it is sufficient to set a compliant representation of Gauss with the central meridian placed at the center of the working area and characterized by a scale factor that induces a cartographic expansion equivalent to that of height, in order to obtain a practically null residual deformation. Add "false origin" values is also advisable to obtain coordinates expressed by small numbers and therefore more manageable, always positive and clearly different between the two coordinates.

\section{Figure 4 - Survey area map with Central Meridian}

After some tests, the desired effects were obtained by imposing the following parameters:

- Central meridian: $11^{\circ} 15^{\prime} 00^{\prime \prime}$ (Fig. 4);

- Central meridian scale factor: 1.000017 ;

- False origin North: $-4840000 \mathrm{~m}$;

- False origin East: $+4000 \mathrm{~m}$.

In the thus defined cartographic representation, the residual deformation has been reduced to values that do not exceed 2 ppm, a quantity that can certainly be neglected even in a highprecision survey as the architectural ones.

\section{CONCLUSIONS}

The presented activities certainly fall within an applicative framework but, in order to guarantee a high standard, in terms of detail of the survey and cartographic reproduction it was necessary to calibrate and design ad hoc solutions. In particular, exploiting sound characteristics of GNSS and Topographic Levelling adopted surveying methodologies, integrating results and elaborating had hoc solutions to overcome local limitations of the TM32 Global Geodetic System a robust control network has been designed. The overall adopted choices guarantee a 1:50 to 1:100 reliable graphical output scale of the cartographic representation.

\section{AUTHOR CONTRIBUTIONS}

Conceptualisation, Francesco Mugnai; methodology, Renzo Maseroli, Francesco Mugnai; software, Renzo Maseroli, Francesco Mugnai; validation, Francesco Mugnai, Renzo Maseroli, Valentina Bonora; formal analysis, Francesco Mugnai, Renzo Maseroli; investigation, Valentina Bonora, Francesco Mugnai; resources, Grazia Tucci, Renzo Maseroli; data curation, Francesco Mugnai; writing - original draft preparation, Francesco Mugnai; writing - review and editing, Francesco Mugnai; visualisation, Franco Maseroli, Valentina Bonora; supervision, Valentina Bonora, Grazia Tucci; project administration, Renzo Maseroli; funding acquisition, Grazia Tucci. All authors have read and agreed to the published version of the manuscript.

\section{REFERENCES}

Abd-elqader, Y. S., Fawaz, D. R. E. M., \& Hamdy, A. M. (2020). Evaluation Study of GNSS Technology and Traditional Surveying in DEM Generation and Volumes Estimation.

Arun, P. S., Ignatious, A. M., Smegha, N. C., \& Sathian, K. K. (2018). Topographic survey and resource mapping using GNSS. Department of Soil and Water Conservation Engineering.

Balletti, C., Galeazzo, G., Guerra, F., \& Monti, C. (2000). Capitolato speciale d'appalto per l'esecuzione di un rilievo in forma numerica alla scala 1: 50 .

Barzaghi R., Borghi A., Carrion D., S. G. (2007). No Title. Bollettino Di Geodesia e Scienze Affini, 3(Firenze), 16.

Barzaghi, R., Betti, B., Carrion, D., Gentile, G., Maseroli, R., \& Sacerdote, F. (2014). Orthometric correction and normal heights for Italian levelling network: a case study. Applied Geomatics, 6(1), 17-25. 
Bo, X. (2008). Research on Application of GPS Leveling [J]. Urban Geotechnical Investigation \& Surveying, 6.

Bonora, V., Tucci, G., Meucci, A., \& Pagnini, B. (2021) Photogrammetry and 3D Printing for Marble Statues Replicas: Critical Issues and Assessment. https://doi.org/10.3390/su13020680

Cefalo, R., Cociancich, A., Di Bartolomeo, M., Ferro, F., Iansig, M., Manzoni, G., \& Montagner, G. (2011). Integrated topographic, GNSS, remote sensing and GIS/WebGIS techniques applied to the study of aquileia river port structures. CEUR Workshop Proceedings, 806(January).

Chenguang, J. (1996). The theoretical studies and preliminary test on accurate calculation of precise trigonometric leveling [j]. Surveying and mapping of sichuan, 3 .

Crainic, G. C. (n.d.). Particular realization cases of topographical details network solved using gnss technology, in forestry. In lucrări ştiinţifice (vol. 52).

Da Silva, I., Ibanez, W., \& Poleszuk, G. (2017). Experience of using total station and GNSS technologies for tall building construction monitoring. International Congress and Exhibition" Sustainable Civil Infrastructures: Innovative Infrastructure Geotechnology", 471-486.

Devoti, R., Pietrantonio, G., \& Riguzzi, F. (2014). GNSS networks for geodynamics in Italy. Física de La Tierra, 26(2014), 11-24.

Guo, Q., Zhao, T., Zhang, C., \& Wu, X. (2017). Digital Topographic Mapping in Urban Obstructed Environment Based on Multi-GNSS Network RTK Technology. Journal of Physics: Conference Series, 910, 012026. https://doi.org/10.1088/1742$6596 / 910 / 1 / 012026$

Halim, S. M. A., Green, M. F. P., Narashid, R. H., \& Din, A. H. M. (2019). Accuracy assessment of TanDEM-X $90 \mathrm{~m}$ digital elevation model in East of Malaysia using GNSS/levelling. 2019 IEEE 10th Control and System Graduate Research Colloquium (ICSGRC), 88-93.

Maseroli, R. (2013). Il nuovo sistema di riferimento geodetico nazionale: stato attuale e prospettive future. Bollettino Della Società Italiana Di Fotogrammetria e Topografia, 1, 67-83.

Mugnai, F., Farina, P., \& Tucci, G. (2021). Exploiting a SemiAutomatic Point Cloud Segmentation Method to Improve the Quality of Rock-Mass Characterization. The Cima Grappa Conservative Restoration Case Study. ISPRS International Journal of Geo-Information, 10(5), 276.

Okiemute, E. S., Ono, M. N., \& Oluyori, P. D. (2018). Comparison of Two Polynomial Geoid Models of GNSS/Leveling Geoid Development for Orthometric Heights in FCT, Abuja.

Oluyori, PD, Ono, MN and Eteje, SO (2018): Comparison of Two Polynomial Geoid Models of GNSS/Leveling Geoid Development for Orthometric Heights in FCT, Abuja. International Journal of Engineering Research and Advanced Technology (IJERAT), 4(10), 1-9.

Oluyori, P. D., Ono, M. N., \& Okiemute, E. S. (2019). Modelling of Orthometric heights from Multi-Networks of
GNSS/Precise Levelling in FCT, Abuja. Oluyori, PD, Ono, MN and Eteje, SO (2019). Modelling of Orthometric Heights from Multi-Networks of GNSS/Precise Levelling in FCT, Abuja. International Journal of Environment, Agriculture and Biotechnology (IJEAB), 4(4), 1173-1180.

Pirsan, R. (2018). Using GNSS technology in general cadastre. Research Journal of Agricultural Science, 50(4), 281-287.

Tarig, A. (2012). Positioning with wide-area GNSS networks: Concept and application. Positioning, 2012.

Veronez, M. R., Florêncio de Souza, S., Matsuoka, M. T., Reinhardt, A., \& Macedônio da Silva, R. (2011). Regional mapping of the geoid using GNSS (GPS) measurements and an artificial neural network. Remote Sensing, 3(4), 668-683.

Wang, B., Wang, W., Li, Y., -, al, Hu, S., Xia, Z., Guo, Q., Zhao, T., Zhang, C., \& Wu, X. (2017). Digital Topographic Mapping in Urban Obstructed Environment Based on MultiGNSS Network RTK Technology Indoor and Outdoor Precision Positioning System Based on Beidou Difference and UWB Digital Topographic Mapping in Urban Obstructed Environment Based on Multi-GNSS Network RTK Technology. IOP Conf. Series: Journal of Physics: Conf. Series, 910, 12026. https://doi.org/10.1088/1742-6596/910/1/012026

Xinsheng, Y. A. N. (2010). A Practical Robust Method for CORS RTK/Leveling [J]. Bulletin of Surveying and Mapping, 12.

Yang, C. A. O., \& Insitute, M. (2013). Research on Application of Combined Model for GPS Leveling. Geomatics \& Spatial Information Technology, 11.

Yang, Y. Y. W. (2007). Discussion on the GPS RTK technique application in the project measurement [J]. Shanxi Architecture, 32 .

Yanrong, W., Lifang, X., \& Mingjuan, G. (2010). The joint application of GPS RTK and total station in terrain mapping. Shandong Coal Science and Technology, 6 . 